\title{
DO THE LANGUAGE ERRORS OF ESL TEACHERS AFFECT THEIR LEARNERS?
}

Norma Nel \& Elana Swanepoel

Unisa

At the University of South Africa (Unisa), a large, open and distance education university in South Africa, the majority of the practising teachers who enrolled as students (henceforth referred to as teacher students) for the practical component of the Advanced Certificate in Education (ACE): Inclusive Education (Learning Difficulties) for the year 2008 lacked English proficiency. Because these students' primary language is not English, they found it difficult to master this course, as reflected by the low throughput rate of 44 per cent in 2008. The question arose: Does poor proficiency in English of English second-language (ESL) teacher students influence ESL learners' progress during learner support lessons taught by teacher students as part of their teaching practice for the ACE: Inclusive Education (Learning Difficulties)?

In an attempt to answer this question, we report on typical errors made by the learners and the teacher students and similarities between teacher errors and learner errors, against the background of a literature overview which includes the relationship between input and output and prominent theories of second-language acquisition.

Departing from a phenomenological/interpretive paradigm, a qualitative analysis of the teacher students' portfolios was undertaken (Hussey \& Hussey, 1997:54). The document analysis was done by means of error analysis of the teacher-student portfolios (which included ESL learner support lessons and ESL learner evidence) that were submitted by the teacher students to Unisa by 1 September 2008.

The results of this study are significant because it alerts academia to the fact that qualified practising ESL teachers are not necessarily proficient in English and that this may have an effect on the ESL learner's ability to acquire English proficiency. However, it was pointed out that several other contributing factors may exist and that further in-depth research is required. Nevertheless, a re-evaluation of teaching methodologies and the upgrading of teacher-students' levels of cognitive academic language skills are required as a matter of urgency.

\section{Keywords}

English second language, transference of language errors, English second-language teachers, English second-language learners, Advanced Certificate in Education students, second-language acquisition, Black South African English, reading levels 


\section{INTRODUCTION}

UNESCO's Education for All Global Monitoring Report (2007) reveals that 77 million primary-school-aged children (three-quarters of them in Africa and Asia) drop out of school or do not attain minimal standards. One of several reasons for this phenomenon in Africa is that the dominant languages (regarded as the norm for education) are English, French and Portuguese - languages that are non-native languages for the majority of the people. In South Africa, English is regarded as a prestigious language and most parents choose to have their children educated in English because they see it as paving the way for success (Bloch, Stein \& Prinsloo, 2001:122). The National Education Policy Investigation of 1992 (1992:13) reported that the majority of South Africans chose English as the language of learning and teaching (LoLT). In South Africa, English is an accepted and widely used language for education, business and government. According to Fleisch (2008:98), 'less than one South African child in ten speaks English as their first language. But by the end of Grade Three most schoolchildren are taught and assessed in the English language'.

In a multilingual country such as South Africa, the largest learner population consists of learners for whom English is a second language and they are referred to as English secondlanguage $\left(\mathrm{ESL}^{1}\right)$ learners or language-minority learners (Walker, Ranney \& Fortune, 2005:323). The fact that most people in developing countries are not proficient in their second language prevents them from fully benefiting from their education (Baloyi, 2002:3).

The National Teacher Education Audit (1995) found that the majority of teachers in South Africa are underqualified or not qualified to teach. They do not have the skills to teach a second language and do not know the principles of bilingual/multilingual education. More recent studies corroborate these findings. In a study that focused on teacher subject knowledge, Taylor and Moyane (2004:38-41) found that 12 out of 23 teachers scored less than 50 per cent in a test that was designed for Grade 6 learners. In a study on teacher pedagogic knowledge, Kühne, Van den Heuvel-Panhuizen and Ensor (2005 in Fleisch, 2008:124) found that teachers had a limited understanding of how learners learn number concepts and of how complex the process is. The teachers simply did not have the language to describe, for example, the developmental stages of number learning. In a study on teachers' ability to read English, Bertram (2006:5-18) found that one third of a sample of teachers in a postgraduate programme at the University of KwaZulu-Natal 'struggled to read to learn'. In a situation analysis of teachers who used ESL as a medium of instruction, Uys, Van der Walt, van der Berg and Botha (2007:77) found that the teachers lacked the knowledge and skills to teach the four language skills and ignored the importance of methodological skills. These teachers were not trained to teach through the medium of English.

At the University of South Africa (Unisa), a large distance education university in South Africa, most of the practising teachers who enrolled as students (henceforth referred to as teacher students) for the practical component of the Advanced Certificate in Education (ACE): Inclusive Education (Learning Difficulties) lacked proficiency in English. Because the majority of these students' primary language is not English, they found it difficult to master this course and the throughput rate was low (44\% passed in 2008). Their portfolios, which formed part of formative assessment, showed that they were not competent to teach their ESL learners adequately. The assumption that can be made from this is that their limited proficiency in English resulted in their poor language skills being transferred to their ESL learners, whose understanding and usage of English were affected. From this assumption, the following research question emerged: 
Does the poor proficiency in English of ESL teacher students' influence ESL learners' progress during their learner support lessons taught as part of their teaching practice for the ACE: Inclusive Education (Learning Difficulties)?

\section{THE RELATIONSHIP BETWEEN INPUT AND OUTPUT}

Second-language acquisition (SLA) requires a 'complex set of skills' and the study of SLA can address different issues, such as learner characteristics, linguistic factors, learning processes, the age of the learner, instructional variables, context of acquisition and purpose of acquisition (Brown, 2007:1-3). A number of factors (such as age; psychological, personality and sociocultural factors; and communicative competence) contribute to the complexity of SLA.

With regard to second-language learning (SLL), Mitchell and Myles (2004:261) postulate that there is no 'one best method' that can be applied at all times and in all situations with any type of learner; however, research that was conducted on SLA offers a great variety of concepts and descriptive accounts, which can assist teachers to understand their classroom experiences, and offer a wide range of pedagogic choices. These authors (2004:257-259) hold that synthesising the work of theorists who try to include all the aspects of SLL into one model does not generally receive support and that, in the future, 'SLL will be treated as a modular phenomenon, with different research programmes addressing different aspects'. This study addresses the influence that teachers' poor English language proficiency has on their ESL learners' acquisition of English as the LoLT. For the purpose of this study, SLA theory (in particular the role of input) is explored.

Schools of thought on SLA have evolved from structural linguistics, behavioural psychology, generative linguistics and cognitive psychology to constructivism (which is a multidisciplinary approach). A social constructivist approach that is relevant to this research is Vygotsky's zone of proximal development, which maintains that children learn, by doing tasks and activities with the assistance of more competent peers or adults (Slavin, 2003:44), through the process of other-regulation (through language) until they are able to take over the new knowledge and skills into their individual consciousness (i.e. from an inter-mental activity to an intra-mental activity). The process whereby supportive dialogue helps the learner to attend to key features in the environment and whereby he or she is prompted, by means of successive steps, is known as scaffolding. Most productive learning takes place in the zone of proximal development and is the domain of knowledge and skill where the learner can achieve the outcome through scaffolding. The learner is not yet able to function independently. Learning is seen first as social and then as individual (Mitchell \& Myles, 2004:195-198). The sociocultural theory stresses the zone of proximal development, scaffolding and activity theory; it applies to SLL and is useful for developing classroom basics such as teacher-student interaction, problem solving and communicative tasks, learner strategy training, and focusing on form and corrective feedback (Mitchell \& Myles, 2004:221 $\& 222)$.

Marinova-Todd (2003:61, 67 \& 70) reviewed several studies and concluded that the availability and access to good second-language input and instruction, not the age of the learner, produce the best outcomes in second-language acquisition. To ensure native-like proficiency, learners need quality second-language instruction. 
Hymes's communicative competence, which is a 'dynamic, interpersonal construct that can be examined by means of the overt performance of two or more individuals in the process of communication' (Brown, 2007:219) and distinguishes between linguistic and communicative competence, is linked to the sociocultural approach to SLA. In an approach that is analogous to this distinction, Cummins (1981 \& 1980) differentiates between cognitive academic language proficiency (CALP) and basic interpersonal communicative skills. CALP is relevant to this study because it includes the context-reduced learning that takes place in classrooms.

In examining the field of SLA, the contrastive analysis hypothesis $(\mathrm{CAH})$ seems relevant to this research because it emphasises that, in SLA, the first-language system can interfere with the second-language system. The $\mathrm{CAH}$ recognises that negative transfer of the native language to the target language can occur and that first-language phonology, as well as the vocabulary and grammatical rules from the native language, might even be represented in the written word of the second language (Brown, 2007:251). In order to develop a theory of SLA, learner variables such as age, cognition, native language, input, affective domain and educational background (Yorio, 1976:61) should be considered. One of these variables is addressed by Krashen's input hypothesis (1985 \& 1997) which comprises a set of five interrelated hypotheses: (1) the acquisition-learning hypothesis; (2) the monitor hypothesis; (3) the natural order hypothesis; (4) the input hypothesis; and (5) the affective filter hypothesis. The input hypothesis claims that SLA occurs as a result of comprehensible input, that is, the acquirer understands the input language and it is not too far beyond his or her current competence (Krashen, 1984:61; 1981:100).

Ellis (2002:243 \& 244) gives three views on the role of input in SLA:

(1) The behaviourist view looks at stimuli and feedback, and ignores the internal processing of the learner. The person who speaks to the learner will model specific language forms and patterns and the learner will internalise and imitate them. The feedback is in the form of positive reinforcement. The input can be manipulated as appropriate stimuli and it ensures adequate feedback. The learner is seen as a passive medium.

(2) The mentalist view considers input as a trigger that sets off internal language processing. The learner has innate knowledge of the possible forms that a language can take. The information that is gained from the input is used to arrive at the forms which apply to the second language, but it is not sufficient to arrive at the rules of the second language.

(3) The interactionist view of the cognitive interactionist sees acquisition as the product of a complex interaction between the linguistic environment of the learners and their internal mechanisms.

A common assumption that underlies these theories is that input has a determining function in the acquisition of language.

Stander (2001:108-110) identified the use of a language transference strategy by secondlanguage speakers (from first language to second language and subsequently to the interlanguage of the speakers) to assist them in learning the second language. In cases where an acquisition strategy for language transference is absent, this can be detrimental to the communication of the second language. The problem is compounded when there is no choice in the first language and the speaker is forced to choose an element from the second language. Transference from one speaker's use of language to another speaker's use of language can be viewed as a contamination factor in the use of the second language. The problem here is that the second-language knowledge of teachers is not always at an acceptable standard for 
teaching purposes and their poor use and knowledge of the language is transferred to the learners. In South Africa this does not apply to Afrikaans only, but also to the other African languages.

From the analysis of the research group's portfolios, it seemed as if language transference had occurred and this will be discussed in the findings.

\section{RESEARCH DESIGN}

\section{Sample}

Some practising teachers enrol for the ACE (which has 16 areas of specialisation, including Inclusive Education) in order to upgrade their three-year professional teaching qualification (a requirement of the Department of Education). Registration as a candidate for the ACE requires that a teacher holds a senior certificate and at least a recognised three-year professional teaching qualification. Purposive and convenient sampling was adopted for this study. The 800 final-year teacher students who were enrolled for the ACE: Inclusive Education (Learning Difficulties) course at Unisa in 2008/2009 formed the sample, which could be divided into two groups: (1) students with English as a first language and (2) students with English as a second language. Only teacher students who had an indigenous African language as their first language and who were teaching ESL learners were included in the research.

\section{Research method and data analysis}

Qualitative analysis of the teacher students' portfolios was done from the phenomenological/interpretive paradigm (Hussey \& Hussey, 1997: 54). The document analysis was done by means of an error analysis of the teacher student portfolios (which included ESL learner support lessons and ESL learner evidence) that were submitted to Unisa by 1 September 2008. The teacher student had to complete practical work for the portfolio (which counted $50 \%$ towards the final pass mark). He or she had to identify a group (two to five) of ESL learners who were in the same grade (grades 3 to 6), spoke the same first language, had similar home backgrounds, whose English proficiency was on approximately the same level and who experienced ESL difficulties. The teacher student had to provide the following evidence in the portfolio: questionnaires for parent and teacher interviews; initial assessments of learners' written English language; error analysis of the written work; eight learner support lessons that were based on the error analysis; examples of learners' written work; and final assessment of learners' written work after the eight support lessons.

A random selection of the 435 qualifying portfolios was made. The teacher students' written errors and their learners' written errors were noted. These errors were compared and analysed to determine to what extent the teachers' language transference influenced their learners' written language. After the seventeenth portfolio, a general tendency of language errors was noted and saturation point was reached, after which continued probing into the portfolios would not have added any further value to the data that was collected.

According to Ellis (2002:48 \& 49), error analysis is an appropriate starting point when studying learner language and SLA. By making use of taxonomies (based on linguistic categories), specific errors are described in detail and a corpus of errors is quantified (Ellis, 
1994:54). The skeleton of English clauses, the auxiliary system, passive sentences, temporal conjunctions and sentential complements is an example of general linguistic categories. Each of the general categories is broken down further into subcategories. More general categories are morphology, syntax and vocabulary. Ellis highlights Corder's (1974) five steps in error analysis research, namely: (1) collection of a sample of learner language; (2) identification of errors; (3) description of errors; (4) explanation of errors; and (5) evaluation of errors. These steps were followed in this research.

Owing to the fact that a variety of factors could influence the errors of the learners, it was necessary to collect well-defined samples of learner language (and teacher student language) in order to accurately identify the types of errors and the conditions under which they appeared. According to Ellis (2002:54-56), this calls for a simple descriptive taxonomy (errors which are most frequent and require the most attention) that is based on linguistic categories which are used for pedagogic purposes. Such taxonomies allow for detailed descriptions of specific errors and quantification of a corpus of errors which guide the teacher in planning learner support. The teacher can choose linguistic categories that correspond to those in structural syllabi and language text books. But are teachers equipped to follow this process, seeing that they themselves make the same errors?

The field of ESL is complex and requires multiple research approaches under which the research questions determine the appropriate method. In this study, the research question required and relied on the description of errors, hence the data were described verbally and the researchers relied strongly on the content of the portfolios.

\section{FINDINGS}

In this study, the researchers looked at the possible transference of language deviations and errors in the language usage of ESL teachers to their learners and the similarities in the language deviations of these two groups. The researchers identified the patterns that underlie the errors of the learners (Table 1) and the teachers (Table 2).

In reading and evaluating the findings, cognisance should be taken of the fact that the participants (teacher students) had already completed the following as part of the syllabus:

The role of the school in relation to learners with learning difficulties; principles for assisting learners with learning difficulties; general principles for assisting learners with learning difficulties and lesson planning; teaching strategies, methods and aids; group assistance; assistance with learning difficulties in the learning areas; assisting learners with language problems, reading problems, written-language problems, English-as-asecond-language problems, mathematical problems, study problems; parent guidance with respect to children with learning difficulties

At the time of the research, the teacher students had already completed three of the five modules of the two-year ACE course through the medium of English. 
Table 1: Errors made by the ESL learners after being taught by the ESL teacher students

\section{$1 \quad$ Phonological errors}

First-language transfer happens particularly on a phonological level because the sound, stress and intonation patterns of the first language are carried over to the second language. This happens when second-language learners are taught by non-first-language speakers of the second language. Black learners tend to make these errors.

sirname - surname: The learner knows the word but perceives the short vowel sound /e:/ as the same. The vowel in both words is phonetically the same, but differs orthographically.

rid - read: English has two high front vowels, the long vowel [i:] and the short vowel [1] as in this minimal pair. The African languages only have one high front vowel [i] and it is therefore difficult for these learners to differentiate between [i:] and [1] when they speak English, hence English minimal pairs that contain these vowels tend to be pronounced in the same way - with [i:].

cheir/chaer - chair: The learner perceives a sound differently.

siste - sister: The sound $/ \mathrm{r} /$ is silent. Unless the learner sees the word and learns its orthographical form, he/she can make this error.

stemps - stamps: A spelling error-sound perception.

Englesh-English: A spelling error and a knowledge deficiency lexical error.

shop - chop: A spelling error.

whilebaroows - wheelbarrows: A spelling error and a knowledge deficiency lexical error.

mada - mother: A phonetic spelling error. The dental fricative does not exist in Zulu and a number of speakers compensate for this by using the sound which is closest to the one that does not exist.

happd-happened: The word is spelled as it is heard.

elso - also: Spelling error.

From - farm. Spelling error.

dear - deer: The learner relies on sound rather than on knowledge of how the word is spelled.

spench-spinach: Poor pronunciation.

\section{Syntactic errors}

Interlingual transfer/first language transfer also occurs on a syntactic level. Many of the second-language learners have a problem with verb tenses in English. The black learners tend to overuse the progressive verb tense (continuous verb tense) in English.

like not - dislike: The arrangement of the items is inappropriate. It could also be a lexical error of a developmental nature which shows that the learner has learned the concept of negation but does not have the lexical item which means the same as not like $=$ dislike.

Grandmom go boy church: The arrangement of words is wrong. It also shows omission of the infinitive and the article, and the wrong tense has been used. This is a good example of an error that would benefit from getting the learner's input, otherwise the interpretation remains plausible.

\section{$3 \quad$ Grammatical error}

Grandma speaks (to) baby. Omission error where the infinitive has been left out.

The cat is in (under) the table: Wrong preposition 'in' instead of 'under'. This is a serious problem for isiZulu speakers. This language has no prepositions, so learners have to learn through practice to master prepositions. 


\section{$4 \quad$ Tense error}

One of them has went home. Because the action has taken place, the learner wants to use the past tense - a typical error for a learner who has not mastered the third person singular that is used for the past; the learner could also be confusing the subject of the sentence as being 'them' and not 'one'.

\section{Transfer error}

Which (what) is the time? The interrogative pronouns 'which' and 'what' are expressed in the same way in most instances in siSwati as ngu (so), ngubani (who is), Ngubani (what is) and ngubani (which is).

\section{$6 \quad$ Difficulty using punctuation marks (capital letters and full stops)}

Table 2: Errors made by the ESL teacher students in reporting on their ESL learners

The context of learning plays a vital role in instances where teaching methods that are used in the classroom can lead to learner errors such as I am having a pain for I have a painthe overuse of the present progressive tense. Teachers who are not proficient in English often do not know which tenses to use in different contexts and consequently teach the form of the tense (e.g. watch - are watching) instead of the function. They teach how to form a particular function instead of when to use a grammatical construction.

\section{Verb tense}

The learners are showed - The learners are shown.

\section{Past tense}

The way she used her study skills made her developed. This is a transfer rule error where in isiZulu the past tense morpheme is attached to the verb as opposed to English where there is an auxiliary - the auxiliary carries the tense marker.

\section{Subject-verb agreement error}

make him likes: 'likes' instead of 'like'

he speak: 'speak' instead of 'speaks'

he doesn't shows - he doesn't show

He read in Sesotho - He reads in Sesotho

help-helps

\section{$4 \quad$ Confusing gender}

he instead of she: In isiZulu there are no equivalent words for 'she' and 'he'.

$5 \quad$ Superlative degree

His handwriting is poor that ... - His handwriting is so poor that ...

There is more improvement to her. For the Sepedi speaker the preposition is a problem.

\section{$6 \quad$ Phonetic errors}

interprete: Confusing pronunciation with orthography.

$7 \quad$ Spelling errors

guesing - guessing; seteces - sentences

\section{Weak expression}

Referred to children with... - Referred to as children with ... Weak expression that arises from difficulty with prepositional phrases.

\section{$9 \quad$ Wrong word/overgeneralisation}

Morphemes are misunderstandable: Wrong word and overgeneralisation of the prefix and suffix rules for forming adjectives. Intralingual transfer: The learner applies a rule in the second language in situations where it does not apply. This happens because the learner overgeneralises a rule and then applies it where it does not apply, for example overgeneralising the adverbial marker on the irregular adverb often to become oftenly. 


\section{Pronunciation}

-abondened - abandoned; spenich - spinach; moaf - mouth; hents - hands

This faulty pronunciation is perpetuated in the learning context because the majority of teachers who teach ESL learners do not speak English as their first language. These teachers, for example, are unable to make the [i:] and [1] distinction. Consequently, the learners' errors of pronunciation reflect features of black South African English which is spoken in the wider community.

\section{Combination of errors}

She could not read a story and show it in a map, she could not answer questions complete, she could not pick important facts in a passage but now there's great improvement. Read(s) a story from a passage and answer(s) questions. ...has mad(e) a very good progress which has noticed and is very much happy about.

Analysis: Many errors can be observed here. First, this teacher makes careless spelling mistakes (e.g. $\operatorname{mad}[e])$. The teacher has a problem with prepositional phrases, for example 'in'. siSwati does not have prepositions and therefore siSwati speakers find it difficult to use prepositions and prepositional phrases in English.

The influence of the first language on second-language learning is evident in these examples.

\section{DISCUSSION}

The transference of common language errors of ESL teacher students (who were enrolled for the ACE: Inclusive Education at Unisa) to their ESL learners in primary schools was the primary concern of this study. In comparing Tables 1 and 2, it seems that both the ESL teacher students and the ESL learners made similar errors. Direct parallel deviations on a phonological, spelling and syntactic level were identified. Other errors included overgeneralisations that comprised intralingual transfer by which the rule was unnecessarily applied in the second language. The causes of these errors and mistakes can be attributed to interference of the first language, overgeneralisation of rules (English), response to complex communication (simplification and omissions) and carelessness. The literature study refers to interference and negative transfer as the contrastive analysis hypothesis (Brown, 2007:251) and Krashan's input hypothesis. In addition, Stander (2001:108-110) refers to the absence of a language transference strategy which leads to contamination of the second language. The two groups in this study were inclined to omit or add prepositions and to confuse gender and tenses. Punctuation and lexical errors were also present in the portfolios.

From the preliminary error analysis, one might think that the research supports Stander's conclusion (2001:110 \& 111): where substantial similarities were identified, the data led to the conclusion that teachers' second-language forms were transferred to their learners and this, in turn, is reflected in students' language usage at tertiary level. However, the similarity in errors does not prove that transference of errors from the ESL teacher student to the ESL learner occurred. A factor that may have contributed to the similarity in errors is the fact that both the ESL teacher students and their ESL learners had the same first language, resulting in a particular second-language variety of English, known as Black South African English (BSAE). De Klerk (2003:463) describes BSAE as the variety of English commonly used by first-language speakers of South Africa's indigenous African languages, while van der Walt (2000:143) points out that different varieties of BSAE can be identified, based on the first 
language of the speaker. De Klerk (2003:467-477) conducted a preliminary analysis on a corpus of Xhosa English by focusing on 20 separate linguistic characteristics, identified as features of BSAE. Many of the errors presented in Tables 1 and 2 are typical of the linguistic characteristics identified by De Klerk in Xhosa English.

With regard to setting a standard in English usage, Pooley (1964:324-325) responds that it is our obligation to the youth we are employed to teach to set a standard, but that standards are approximations within a range of latitude and tolerance. In South Africa, Standard English (as taught at Universities and used in the business world) holds the key to economic advancement (De Klerk, 2003:478). The adherence to a level of Standard English for academic purposes would thus be desirable. As a higher education institution it would be our obligation to ensure that the ESL teacher students adhere to this standard. Whether allowance should be made for different varieties of South African English is a contentious issue, but since standards for these different varieties have not yet been finalised, this paper will not enter this debate. However, Parkinson and Singh (2007:63) suggest that students should be sensitised to the differences between Standard English and BSAE so that they can distinguish the different forms, while taking care not to devalue the BSAE varieties.

The ESL teacher is the role model of the ESL learner and should therefore be equipped with a thorough knowledge of English and have thorough training in both the prescriptive and the descriptive fields of the language (Higgens, 1964:331). Judging from the language errors listed in Tables 1 and 2, there seems to be a deficiency in the linguistic training of these teachers. The ESL teacher students do not seem to have acquired the requisite level of competency in English and the learners are not receiving language correction because the teacher students probably do not perceive the learners' language as 'wrong'; that is, they do not hear these errors and, secondly, they may not know how to deal with such errors. Fleisch (2008:123) points out that one of the most important factors that influence learner performance is what teachers know. In line with Vygotsky's zone of proximal development, the learners are not learning to be more proficient in English because they are not assisted by more competent adults.

Another factor which may contribute to the language errors revealed by both the ESL teachers and the ESL learners is low reading ability. Pretorius (2002:91) examined the relationship between reading ability and academic performance of students and found that the reading score was the strongest predictor of academic performance, compared to matric results, study habits, level of motivation, and locus of control. She (2002:98) explains that ESL students who are poor academic performers are usually poor readers and that they, unless their reading levels are improved, will not develop the requisite linguistic-cognitive skills for constructing meaning so that they can read to learn. She warns (2002:100) that 'teachers with low-reading levels may teach students to read superficially and so perpetuate the negative cycle of Matthew effects in our schools'.

In-depth research is needed to identify the various factors contributing to this problem and to determine the effect of these factors in order to remedy the situation through the development of intervention strategies to be implemented at Unisa to improve the throughput rate of ACE: Inclusive Education teacher students by enhancing their English-language proficiency. 


\section{RECOMMENDATIONS}

The fact that these language errors occurred in the portfolios of qualified practicing ESL teachers teaching ESL learners is disconcerting. From the research findings, it follows that practising teachers who have enrolled for the ACE are themselves in need of corrective measures and interventions that will enable them to acquire English proficiency before they can even be expected to help their ESL learners. The practical knowledge base of teachers should be grounded in theory and principles and should be informed by effective language and content teaching that is appropriate for the different stages of a programme and teachers' development (Cloud, 2005:279 \& 280). Consideration should be given to various concepts and descriptive accounts to enable teachers to understand their classroom experiences and offer pedagogic choices (Mitchell \& Myles, 2004:261). In addition, teachers should be trained to teach through the medium of English as they have been seen to lack the knowledge and skills to teach the four language skills and ignore the importance of methodological skills (Uys et al., 2007:77). The reading ability of students at tertiary level institutions should be tested and their reading skills developed (Pretorius, 2002:101).

Whereas research tends to focus on primary school learners, grade 8 learners and students, this study highlights the fact that more research into the language proficiency of practicing ESL teachers is needed, as well as a more comprehensive study into the effect that a low level of language proficiency of ESL teachers has on ESL learners.

The results of this study are significant and the research is relevant, useful and timely, because it alerts academia to the extent and impact of the qualified practising ESL teachers' low level of English proficiency and its possible effect on the ESL learner's ability to acquire English proficiency. Further research is necessary in order to identify the critical contributing factors and to develop a multifaceted solution to the problem, including a re-evaluation of teaching methodologies. A two-tiered approach is needed: firstly, the teacher student's level of English proficiency should be raised and, secondly, guidelines should be developed to improve learner support lessons presented in teacher students' practical teaching portfolios to ensure that ESL learners are taught effectively.

Many higher academic institutions support first-year ESL students by assisting them in upgrading their cognitive academic language skills. The research indicates that even students with three-year qualifications might require assistance in upgrading their CALP.

\section{Acknowledgement}

We wish to thank the following professionals:

$N$ Sindela, from the Department of English Studies at the University of South Africa, for analysing the language errors of the ESL teacher students and the ESL learners

Prof L Barnes, Department of Linguistics, University of South Africa

Note:

1. The curriculum names this the first additional language and refers to the first language as home language. 


\section{REFERENCES}

BALOYI, M. 2002. English a learning barrier. Daily News. 1 August:3.

BERTRAM, C. 2006. Exploring teachers' reading competences: a South African case study. Open Learning 21(1):5-18.

BLOCH, C, P STEIN \& M PRINSLOO. 2001. Progress report on the Children's Early Literacy Learning (CELL) research project in South Africa. Journal of Early Childhood Literacy 1(1): $121 \& 122$.

BROWN, HD. 2007. Principles of language learning and teaching. White Plains, NY: Pearson Longman.

CLOUD, N. 2005. The dialogic process of capturing and building teacher practical knowledge in dual language programs. In Tedick, DJ (Ed), Second-language teacher education. London: Lawrence Erlbaum: 273-280.

CORMANY, S, C MAYNOR \& J KALNIN. 2005. Developing self, developing curriculum, and developing theory: researchers in residence at Patric Henry Professional Practice School. In Tedick, DJ (Ed), Second language teacher education. London: Lawrence Erlbaum. 215-230.

CUMMINS, J. 1980. The cross-lingual dimensions of language proficiency: implications for bilingual education and the optimal age issue. TESOL Quarterly, 14:175-187.

CUMMINS, J. 1981. The role of primary language development in promoting educational success for language minority students. Sacramento: California State Department of Education, Office of Bilingual Bicultural Education.

DE KLERK, V. 2003. Towards a norm in South African Englishes: the case for Xhosa English. World Englishes, 22(4):463-481.

ELLIS, R. 2002. The study of second language acquisition. Oxford: Oxford University Press.

ELLIS, R. 1994. The study of second language acquisition. Auckland: Oxford University Press.

FLEISCH, B. 2008. Primary education in crisis: why South African schoolchildren underachieve in reading and mathematics. Cape Town: Juta.

HIGGENS, VL. 1964. Approaching usage in the classroom. In Allen, HB (Ed), Readings in applied English Linguistics. New York: Appleton-Century-Crofts.

HUSSEY, J \& R HUSSEY. 1997. Business research: a practical guide for undergraduate and postgraduate students. Hampshire: Palgrave.

KAPP, R. 2004. 'Reading on the line': an analysis of literacy practices in ESL classes in a South African township school. Language and Education, 18(3):246-263.

KRASHEN, S. 1981. Second language acquisition and second language learning. Oxford: Pergamon.

KRASHEN, S. 1984. Immersion: why it works and what it has taught us. Language and Society, 12:61-64.

KRASHEN, S. 1985. The input hypothesis. London: Longman.

KRASHEN, S. 1997. Foreign language education: the easy way. Culver City, Calif: Language Education Associates. 
MACARO, E. 2003. Teaching and learning a second language. New York: Continuum.

MARINOVA-TODD, SH. 2003. Know your grammar: what the knowledge of syntax and morphology in an L2 reveals about the critical period for Second/Foreign language acquisition. In Mayo, M \& M Lecumberri (Eds), Age and the acquisition of English as a foreign language. Clevedon: Multilingual Matters Ltd. 59-73.

MERRIAM, S. 1998. Qualitative research and the case study applications in education. San Francisco: Jossey-Bass.

MITCHELL, R \& F MYLES. 2004. Second language learning theories. London: Arnold.

NATIONAL EDUCATION POLICY INVESTIGATION. 1992. Language Report of the NEPI Language Group. Cape Town: Oxford University Press.

PARKINSON, J \& V SINGH. 2007. Stability of grammatical features of Black South African English. Per Linguam, 23(2):54-67.

POOLEY, RC. 1994. Dare schools set a standard in English usage? In Allen, HB (Ed), Readings in applied English Linguistics. New York: Appleton-Century-Crofts.

PRETORIUS, EJ. 2002. Reading and applied linguistics - a deafening silence? South African Linguistics and Applied Language Studies, 20:91-103.

RICHARDS, JC. 1993. The dilemma of teacher education in second language teaching. In Richards, JC \& D Nunan (Eds), Second language teacher education. Australia: Cambridge University Press. 3-13.

SLAVIN, R. 2003. Educational psychology: theory and practice. Boston: Allyn \& Bacon.

STANDER, M. 2001. Taaloordrag in the onderrig van Afrikaans as tweede taal. Literator, 22(3):107-122.

TAYLOR, N \& J MOYANE. 2004. 'Khanyisa Education Support Programme: Baseline study Part 1: Communities, Schools and Classrooms’ Memorandum (April 2005):38-41.

UNESCO. 2007. Education for all global monitoring report. United Nations: Unesco Publishing.

UYS, M, J VAN DER WALT, R VAN DEN BERG \& S BOTHA. 2007. English medium of instruction: a situation analysis. South African Journal of Education, 27(1):69-82.

VAN DER WALT, C. (2000). The international comprehensibility of varieties of South African English. World Englishes, 19(2):139-153.

WALKER, CL, S RANNEY \& TW FORTUNE. 2005. Preparing preservice teachers for English language learners: a content-based approach. In Tedick, DJ (Ed), Second language teacher education,. London: Lawrence Erlbaum. 313-333.

YORIO, C. 1976. Discussion of 'Explaining sequence and variation in second language acquisition'. Language Learning, special issue 4:59-63. 


\section{BIOGRAPHICAL NOTE}

Norma Nel is a senior lecturer in the Department of Further Teacher Education at the University of South Africa. Her research interests include inclusive education, barriers to learning, English second language and learner support. Email: nelnm@unisa.ac.za.

Elana Swanepoel is a senior lecturer in the Department of Business Management at the University of South Africa. Her research interests include the education of English second language business management students, entrepreneurship and management. Email: swanee@unisa.ac.za. 